\title{
Maintenance Long-Term Multiple Cycles Treatment with Docetaxel in Metastatic Castration-Resistant Prostate Cancer: A Report of Three Cases
}

\author{
Jian-zhou Cao $\mathbb{D}^{1,2}$ \\ Jin-feng $\operatorname{Pan}\left(\mathbb{D}^{1,2}\right.$ \\ Derry Mingyao $\mathrm{Ng}^{1,3}$ \\ Meng-qi Ying (D) \\ Jun-hui Jiang ${ }^{4,5}$ \\ Qi Ma $(\mathbb{D})^{2-5}$
}

'Medical School, Ningbo University, Ningbo, Zhejiang, 3152II, People's Republic of China; ${ }^{2}$ Comprehensive Urogenital Cancer Center, Ningbo First Hospital, The Affiliated Hospital of Ningbo University, Ningbo, Zhejiang, 315010, People's Republic of China; ${ }^{3}$ Translational Research Laboratory for Urology, The Key Laboratory of Ningbo City, Ningbo First Hospital, The Affiliated Hospital of Ningbo University, Ningbo, Zhejiang, 3150I0, People's Republic of China; ${ }^{4}$ Department of Urology, Ningbo First Hospital, The Affiliated Hospital of Ningbo University, Ningbo, Zhejiang, 3I50I0, People's Republic of China; ${ }^{5}$ Ningbo Clinical Research Center for Urological Disease, Ningbo, Zhejiang, 315010, People's Republic of China

Correspondence: Jun-hui Jiang; Qi Ma Ningbo First Hospital, 59 Liuting Street, Ningbo, Zhejiang, 3I50I0, People's Republic of China

Tel +86 I39678 I0338; +86 I595880097|

Email Jiangjh200509@I26.com;

dr.qm@qq.com

\begin{abstract}
Prostate cancer $(\mathrm{PCa})$ is one of the most common types of malignancy, most patients with $\mathrm{PCa}$ will eventually progress to metastatic castration-resistant prostate cancer (mCRPC), which has a poor prognosis. Since 2004, chemotherapy has been approved by the FDA as the first-line treatment for mCRPC, and docetaxel-based regimens have been shown to improve both the patients' symptoms and overall survival (OS). 10 cycles of docetaxel therapy are usually given to patients with mCPRC, but there is still no consensus on the optimal number of treatment cycles. Here, we present three cases of mCRPC patients that received maintenance long-term multiple-cycles docetaxel treatment. We believe that this new treatment strategy may benefit carefully selected mCRPC patients and provide several key advantages such as maximum exposure to drugs, improvements in drug efficacy, and reduce the risk of developing drug resistance.
\end{abstract}

Keywords: metastatic castration-resistant prostate cancer, docetaxel, maintenance long-term multiple chemotherapy

\section{Introduction}

$\mathrm{PCa}$ is one of the most common forms of malignancy in men and is the second leading cause of cancer-related death in Western countries. The incidence and mortality rates have been increasing in most Asian countries, possibly due to the increased use of prostate-specific antigen(PSA) testing, an aging population, and the increasing popularity of the westernized diet. ${ }^{1}$ Although most patients with metastatic $\mathrm{PCa}$ respond to medical or surgical castration, the disease eventually progresses to mCRPC within 2-3 years. ${ }^{2-4}$

Since 2004, multiple studies have demonstrated that drugs such as docetaxel, abiraterone, enzalutamide, cabazitaxel, radium-223 dichloride, and sipuleucel-T can increase the OS of patients with $\mathrm{mCRPC}$, and these drugs have also been approved by the Food and Drug Administration(FDA). ${ }^{5}$ Based on the TAX327 and SWOG9916 trials, docetaxel with prednisone has become the mainstay of treatment in mCRPC. ${ }^{6,7}$ Usually, 10 cycles of docetaxel therapy are given to patients with mCPRC as the standard therapy, ${ }^{8}$ before or after chemotherapy new hormanal therapy drugs, such as abiraterone and enzalutamide, either for convenience or to reduce the risk of cumulative side effects. However, the optimal number of docetaxel cycles needed to achieve a significant survival benefit in patients has not yet been determined. In a retrospective study, Morree 
et al showed that treatment with $\geq 8$ cycles of docetaxel may be associated with a better OS than with fewer cycles in patients with mCRPC. ${ }^{9}$ A single-center clinical trial in Japan also showed an improved prognosis in mCRPC patients with long-cycles docetaxel therapy. ${ }^{10}$ These findings provided a clue for determining the optimal number of docetaxel cycles.

Here we reported three patients from our department with continuous multiple cycles therapy of mCRPC by docetaxel. These patients' clinical characteristics are summarized in Table 1. We define this treatment strategy as maintenance long-term multiple cycles docetaxel therapy and we believe that this strategy is a reasonable choice for carefully selected mCRPC patients.

\section{Case I}

The first patient is a 63-year-old man, who had an initial PSA level of $200 \mathrm{ng} / \mathrm{mL}$ in 2016, and an Eastern cooperative oncology group (ECOG) score of $\leq 1$. The imaging examination indicated that the PCa had broken through the left capsule of the prostate. Multiple bone metastases were also detected using the bone Emission Computed Tomography (ECT) scan. Subsequently, the prostatic biopsy revealed that the patient had a poorly differentiated adenocarcinoma and the Gleason score was $4+5=9$. He was diagnosed as prostate cancer $\left(\mathrm{T}_{3 \mathrm{a}} \mathrm{N}_{1} \mathrm{M}_{1 \mathrm{~b}}\right)$. Bicalutamide combined with Goserelin (BG) treatment was initiated. After 3 months of BG treatment, his PSA level kept increasing and the cancer progressed to the mCRPC stage. Next, he received docetaxel $75 \mathrm{mg} / \mathrm{m}^{2}$ every 3 weeks with prednisone $5 \mathrm{mg}$ twice daily. Zoledronic acid was also administered to protect his bones. After the first cycle of docetaxel, his PSA levels dropped from 190ng/ $\mathrm{mL}$ to $148 \mathrm{ng} / \mathrm{mL}$. By the 7 th cycle, a review of his bone ECT (Figure 1A) revealed that the patients' multiple bone metastases were still stable and the patients' PSA level was $49 \mathrm{ng} / \mathrm{mL}$. As the chemotherapy cycles continued, his PSA levels continued to decrease. By the 28th cycle, the patients' PSA level was $0.5 \mathrm{ng} / \mathrm{mL}$ (Figure 1B) and imaging examination showed significant remission. However, as the treatment cycle continued, the patient's PSA level started to increase at the 33rd cycle. At that time, the patients' ECOG score was $\leq 1$. The patients' treatment was then switched to abiraterone combined with prednisone and is currently still ongoing at the time of writing. In summary, the patient could tolerate 33 cycles of docetaxel chemotherapy. His PSA response was obvious, imaging

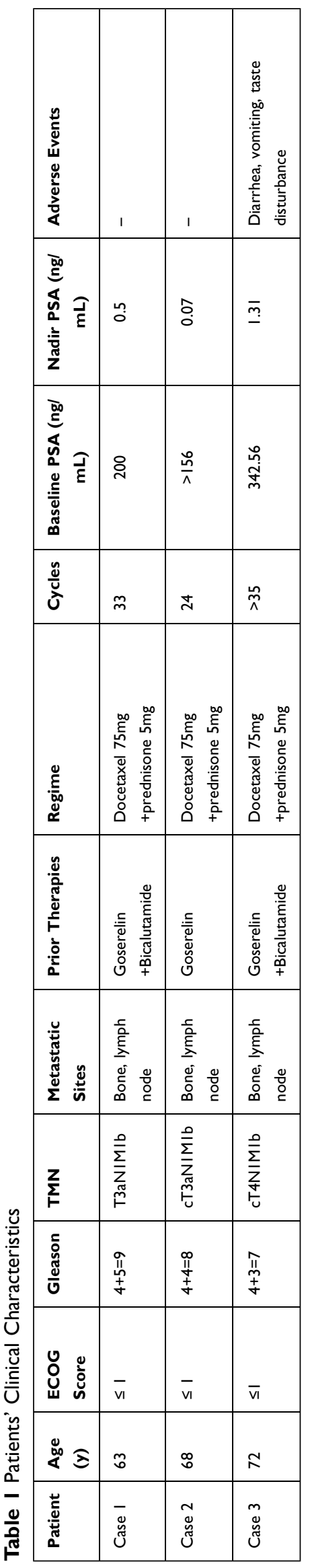




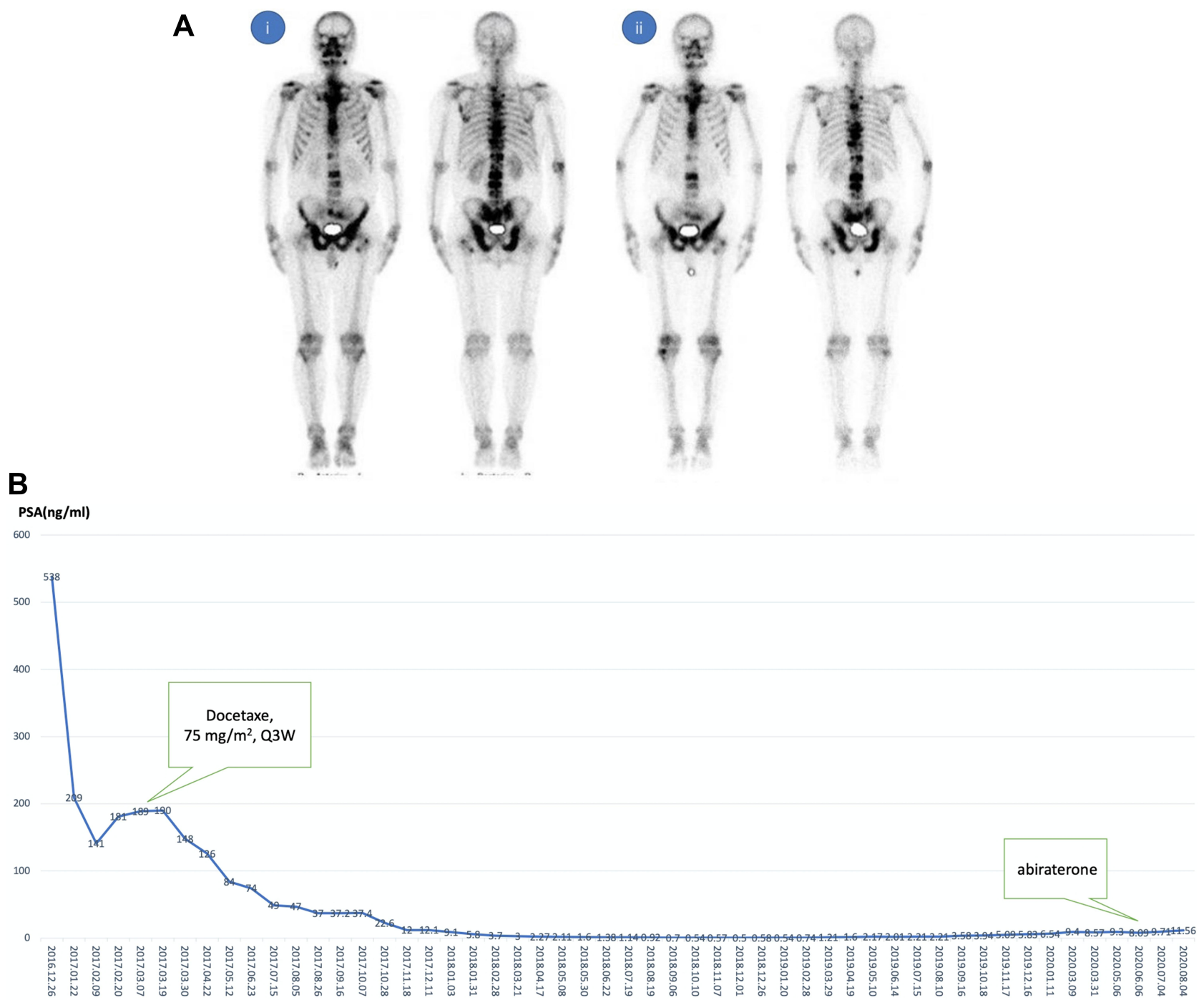

Figure I Bone metastases and PSA responses after receiving maintenance long-term multiple cycles docetaxel chemotherapy in patient I. (A) After the 7th cycle, bone ECT showed significant remission of bone metastasis in patient I. (i) Baseline of docetaxel administration, (ii) after 7 cycles of docetaxel administration. (B) The curve of PSA changes and chemotherapy cycles in patient I. The patient received maintenance docetaxel chemotherapy for a total of 33 cycles. During the treatment, the PSA level of the patient was monitored regularly.

showed definite remission, and his quality of life (QoL) did not decrease significantly.

\section{Case 2}

The next patient is a 68-year-old man who had an initial PSA level of $156 \mathrm{ng} / \mathrm{mL}$ in 2017 with an ECOG score of $\leq 1$. A prostate biopsy was performed and the Gleason score was $4+4=8$. The clinical stage was $\mathrm{cT}_{3 \mathrm{a}} \mathrm{N}_{1} \mathrm{M}_{1 \mathrm{~b}}$. After the cancer progressed into mCRPC, docetaxel $75 \mathrm{mg} / \mathrm{m} 2$ every $3 \mathrm{wk}$ with prednisone $5 \mathrm{mg}$ twice daily was administered to the patient as the first-line treatment, combined with Goserelin and zoledronic acid. During the first two chemo-cycles, the patient's PSA increased, likely due to the PSA flare-up phenomenon from the initial chemotherapy. Fortunately, as the docetaxel therapy cycles continued, the patients' PSA levels began to decline, eventually dropping to $0.07 \mathrm{ng} / \mathrm{mL}$ at the 12 th cycle. Patients' bone scans were reviewed every six months, and it showed that the patients' bone metastases were reduced significantly (Figure 2). Palliative radiotherapy was administered locally to the prostate and seminal vesicles after the 17th chemotherapy cycle. Progression of the disease was observed at the 24th cycle of maintenance chemotherapy. During this period, the ECOG score of the patient was $\leq 1$. The patient did not develop granulocytopenia, hair loss, fatigue, or any gastrointestinal reactions. After docetaxel failure was observed, abiraterone 1000mg once daily combined with prednisone $5 \mathrm{mg}$ twice daily was administered. 

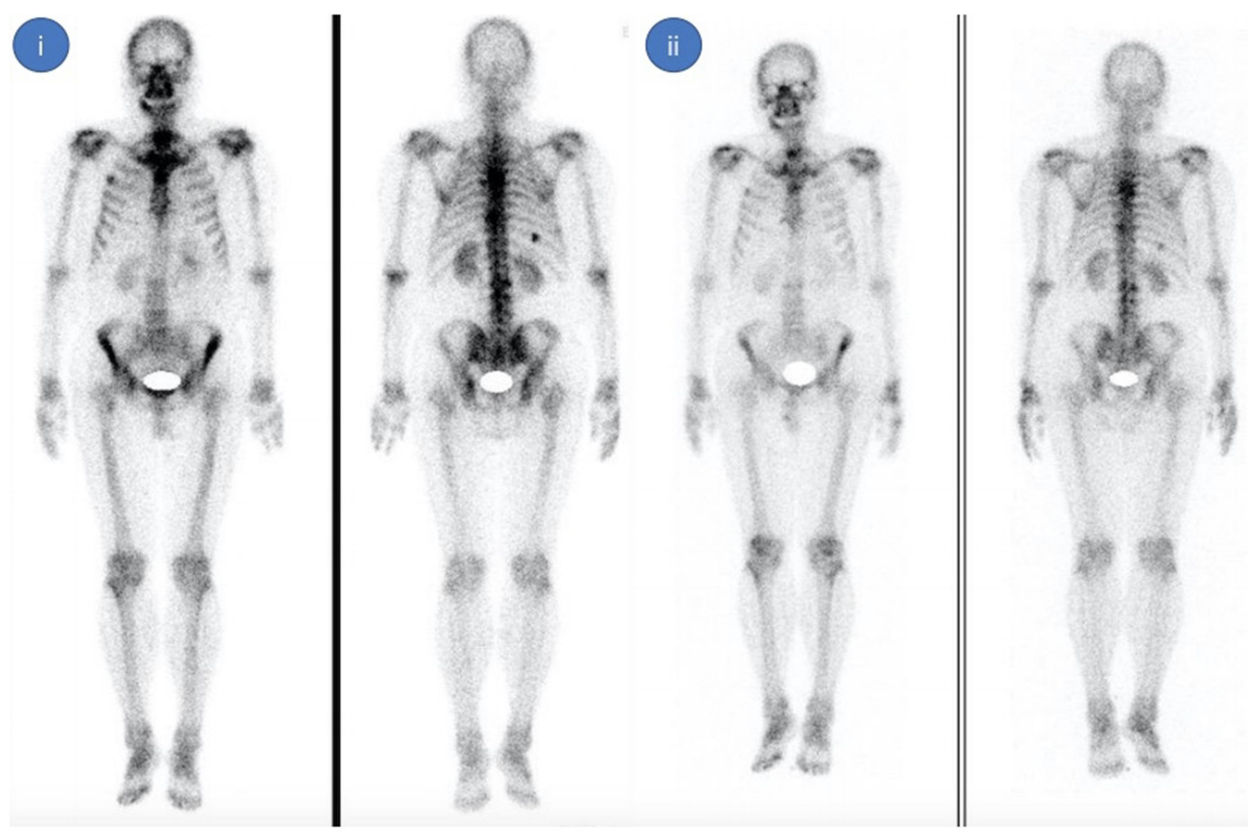

Figure 2 Bone metastases response after receiving maintenance long-term multiple cycles docetaxel chemotherapy in patient 2 . After 14 cycles of docetaxel administration, bone ECT showed significant remission of bone metastasis in patient 2. (i) Baseline of docetaxel administration, (ii) after 14 cycles of docetaxel administration.

\section{Case 3}

The last case is a 72-year-old man who underwent a prostate biopsy with an initial PSA of $342.56 \mathrm{ng} / \mathrm{mL}$ in 2013. Pathological findings revealed a moderately differentiated adenocarcinoma with a Gleason score of $4+3$. The patient was given a systemic evaluation, as the prostate cancer has already invaded to the seminal vesicle and bladder, the patient also had both pelvic lymph node enlargement and multiple bone metastases. The clinical-stage was $\mathrm{cT}_{4} \mathrm{~N}_{1} \mathrm{M}_{1 \mathrm{~b}}$. After 5 years of receiving castration therapy, the patients' cancer progressed to $\mathrm{mCRPC}$ and his PSA levels increased to $46.53 \mathrm{ng} / \mathrm{mL}$. Docetaxel $75 \mathrm{mg} / \mathrm{m}^{2}$ every 3 weeks combined with prednisone $5 \mathrm{mg}$ twice daily and zoledronic acid were administered to the patient. Since the initiation of the docetaxel treatment, a steady decline in PSA level has been observed (Figure 3). Until the 26 th cycle, the patients' PSA level was $1.31 \mathrm{ng} / \mathrm{mL}$. Diarrhea, vomiting, taste disturbance, and other grade 1 and grade 2 adverse events (AEs) occurred during the duration of the patient's docetaxel therapy. At the time of writing, the patient's PSA level was stable and his quality of life (QoL) was relatively good. No obvious progression of the disease was observed using imaging evaluation. To date, the patient has undergone 35 cycles of maintenance long-term chemotherapy.

\section{Discussion}

In 2004, two landmark studies TAX-327 ${ }^{6}$ and SWOG-9916 ${ }^{3}$ demonstrated that docetaxel-based chemotherapy could prolong the OS of mCRPC patients, which led to the approval of docetaxel as the first-line treatment for mCRPC. Currently, there is no consensus on the optimal number of cycles of treatment. ${ }^{11}$ In the TAX 327 and SWOG 9916 studies, the number of cycles was limited to 6-10 cycles, mainly due to toxicity considerations and disease progression concerns. ${ }^{2}$ Morree has identified that the total number of docetaxel cycles delivered was an independent factor for patient OS. Patients who received more than 10 cycles had a median OS of 33.0 months compared with 26.9 months in patients who received 8 to 10 cycles; patients who received 5 to 7 cycles had a median OS of 22.8 months. ${ }^{9}$ Furthermore, a clinical trial from Taiwan confirmed that mCRPC patients with $>10$ cycles of docetaxel chemotherapy had a longer OS time (22.7 months vs 13.4 months) compared to patients who received $<10$ cycles. $^{12}$ Kongsted et $\mathrm{al}^{13}$ also reported that treatment with $>9$ cycles of docetaxel was found to be an independent predictor of OS. Taken together, increasing the number of docetaxel therapy cycles while maximizing exposure to docetaxel-based chemotherapy might improve the OS of mCRPC patients.

There are two ways to achieve maximum exposure to docetaxel-based chemotherapy. One is intermittent docetaxel therapy and the other is continuous docetaxel therapy. For intermittent docetaxel therapy, infusion of docetaxel is stopped when disease stabilization is observed; upon progression (PSA and/or clinical progression), treatment is restarted until the disease is resistant to 


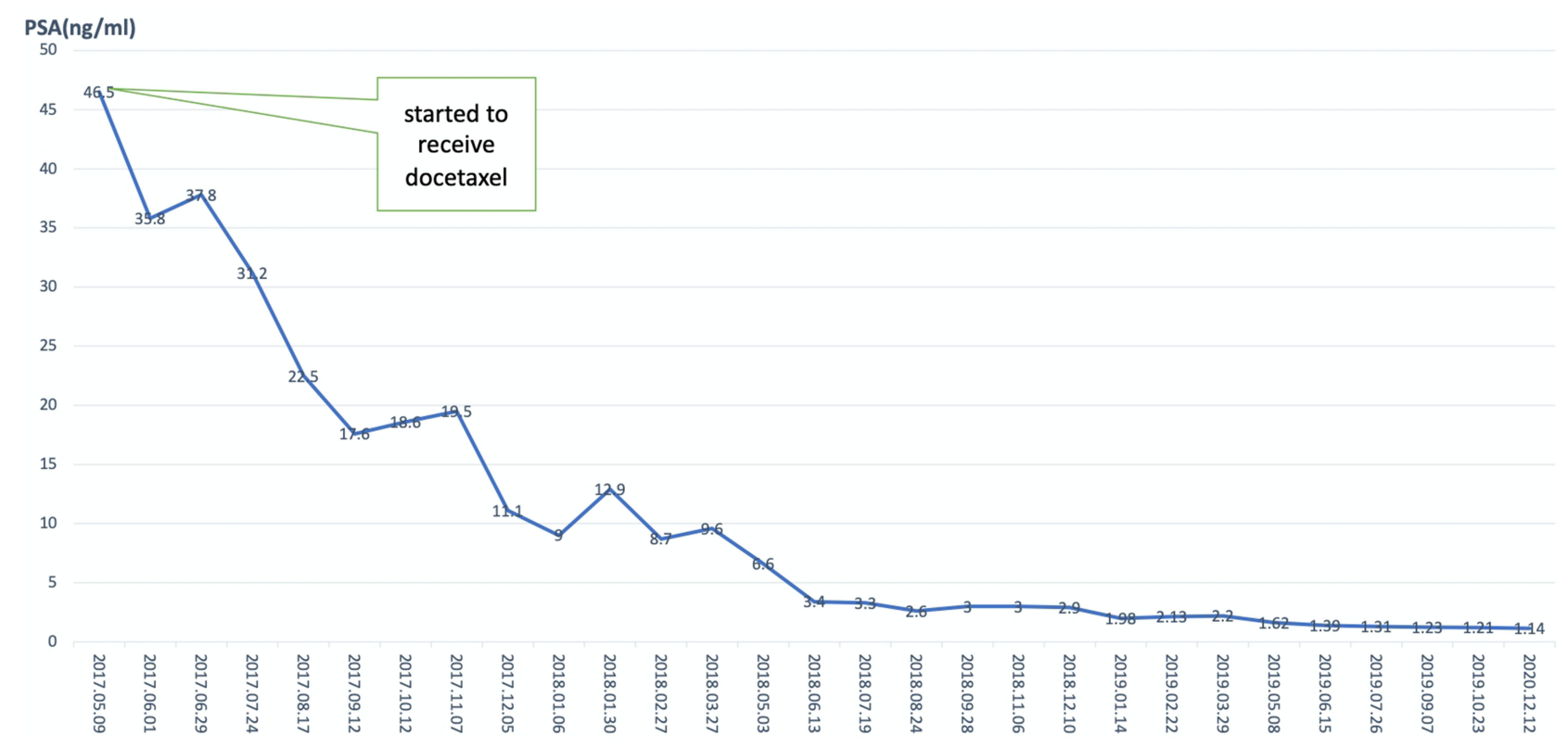

Figure 3 PSA response after receiving long-term multiple cycles docetaxel administration in patient 3 . The patients received maintenance docetaxel chemotherapy for a total of 35 cycles. The PSA level of the patient was monitored regularly after docetaxel therapy. At the time of writing, the patient was still being treated with docetaxel.

docetaxel and progresses. For continuous docetaxel therapy, docetaxel is continuously infused in every cycle until the disease eventually progresses. Currently, most studies about maximizing exposure to docetaxel in prostate cancer are based on intermittent docetaxel therapy. ${ }^{8,14-16}$

However, theoretically, continuous therapy may have better results compared to intermittent therapy. ${ }^{17}$ A Phase III clinical trial (PRINCE) ${ }^{18}$ compared continuous docetaxel therapy with intermittent docetaxel therapy in patients with mCRPC. Although the one-year survival showed that intermittent docetaxel therapy was not inferior to continuous docetaxel therapy, the median OS of continuous docetaxel was better than that of intermittent docetaxel (19.3 mouths vs 18.3mouths). Animal model-based studies also found that intermittent docetaxel therapy was more likely to result in developing drug resistance compared to continuous docetaxel therapy. ${ }^{19}$

Few studies have been reported on long-term multiple cycles of continuous docetaxel chemotherapy. Takahashi et al reported two cases with continuous lone-term docetaxel therapy in mCRPC patients. ${ }^{20}$ In their report, two patients received over 70 cycles of docetaxel chemotherapy. However, the docetaxel dose was significantly reduced in both cases and they continued to administer docetaxel even after the disease has progressed. Unlike their study, in our report, all three patients received the standard dose of docetaxel, and its administration was stopped when the disease was observed to have progressed. Therefore, our report is potentially a better reflection on the efficacy and safety of continuous long-term multiple cycles of docetaxel administration in carefully selected mCRPC patients. A major concern for continuous lone-term multiple cycles maintenance chemotherapy is docetaxel-related toxicity. However, in all of our cases, the treatment was well-tolerated and they all had good QoL.

Another strategy for docetaxel chemotherapy is docetaxel rechallenge. A few studies have demonstrated that docetaxel rechallenge is a viable treatment option for patients who have a progression-free interval of $>6$ months and $\mathrm{a} \geq 50 \%$ reduction in PSA levels during the first-line chemotherapy with docetaxel. ${ }^{21-23}$ In a retrospective series of 46 patients, Caffo and colleagues were able to show that a progression-free interval of $>6$ months was a positive independent predictor for $\mathrm{OS}^{22}$ Although docetaxel rechallenge is a therapeutic option for selected patients, the risk of cumulative toxicity as described in literature should receive careful consideration.

Regarding the selection process for mCRPC patients who are suitable for maintenance long-term multiple cycles of docetaxel therapy? Among the three patients 
receiving long-term maintenance multiple cycles chemotherapy at our center, the following characteristics were observed: (1) A decrease in PSA levels during the early cycles (except during a PSA flare). (2) At the 10th cycle of chemotherapy, the PSA levels continued to decline, and these patients may continue to benefit from docetaxel. (3) Patients' performance was good and their QoL did not decrease significantly after receiving multiple cycles of chemotherapy. (4) No AEs such as serious myelosuppression, febrile neutropenia, and gastrointestinal discomfort occurred during chemotherapy.

In summary, we propose a new treatment strategy called long-term maintenance docetaxel multiple cycles chemotherapy, which may benefit carefully selected mCRPC patients. This treatment strategy provides the advantages of maximum drug exposure, improvement of efficacy, and a lower probability of developing drug resistance. More clinical trials are needed to demonstrate the safety and efficacy of long-term maintenance multiple cycles of docetaxel therapy in selected mCRPC patients.

\section{Statement of Ethics}

The Ningbo First Hospital of Ethical Committee on human research approved to publish the case details. All patients gave written informed consent to have their case details and any accompanying images published.

\section{Funding}

This study was supported by Zhejiang Natural Science Fund (Grant No.LY20H050002 to Q.M, Grant No. LY18H05000 to JHJ). Ningbo Natural Science Foundation (Grant No.2018A610297 to QM), and the Fund of Ningbo Clinical Research Center for Urological Disease (2019A21001).

\section{Disclosure}

The authors report no conflicts of interest in this work.

\section{References}

1. Kimura T, Egawa S. Epidemiology of prostate cancer in Asian countries. Int J Urol. 2018;25(6):524-531. doi:10.1111/iju.13593

2. Tannock I, de Wit R, Berry W, et al. Docetaxel plus prednisone or mitoxantrone plus prednisone for advanced prostate cancer. $N$ Engl $J$ Med. 2004;351(15):1502-1512. doi:10.1056/NEJMoa040720

3. Petrylak D, Tangen C, Hussain M, et al. Docetaxel and estramustine compared with mitoxantrone and prednisone for advanced refractory prostate cancer. N Engl J Med. 2004;351(15):1513-1520. doi:10.1056/ NEJMoa041318
4. Zhou T, Zeng S, Ye D, et al. A multicenter, randomized clinical trial comparing the three-weekly docetaxel regimen plus prednisone versus mitoxantone plus prednisone for Chinese patients with metastatic castration refractory prostate cancer. PLoS One. 2015;10(1): e0117002. doi:10.1371/journal.pone.0117002

5. Mohler J, Antonarakis E, Armstrong A, et al. Prostate cancer, version 2.2019, NCCN clinical practice guidelines in oncology. J Natl Compr Canc Netw. 2019;17(5):479-505. doi:10.6004/jnccn.2019.0023

6. Zhang H, Ye D, Yao X, et al. Docetaxel plus prednisone versus mitoxantrone plus prednisone for metastatic hormone-refractory prostate cancer in Chinese patients: experience of a single center. Urol Int. 2007;79(4):307-311. doi:10.1159/000109714

7. Porsch M, Ulrich M, Wendler J, et al. A randomised phase II trial comparing docetaxel plus prednisone with docetaxel plus prednisone plus low-dose cyclophosphamide in castration-resistant prostate cancer. Chemotherapy. 2014;60(2):129-134. doi:10.1159/000369781

8. Gyawali B, Koomulli-Parambil S, Iddawela M. Continuous versus intermittent docetaxel for metastatic castration resistant prostate cancer. Crit Rev Oncol Hematol. 2016;102:118-124. doi:10.1016/j. critrevonc.2016.04.014

9. de Morrée E, Vogelzang N, Petrylak D, et al. Association of survival benefit with docetaxel in prostate cancer and total number of cycles administered: a post hoc analysis of the mainsail study. JAMA Oncol. 2017;3(1):68-75. doi:10.1001/jamaoncol.2016.3000

10. Miyamae K, Kitani K, Hara K, et al. [Clinical study of long-term docetaxel based chemotherapy treatment for patients with castration-resistant prostate cancer]. Nihon Hinyokika Gakkai Zasshi. 2014;105(4):172-177. Japanese. doi:10.5980/ jpnjurol.105.172

11. Armstrong A, George D. Optimizing the use of docetaxel in men with castration-resistant metastatic prostate cancer. Prostate Cancer Prostatic Dis. 2010;13(2):108-116. doi:10.1038/pcan.2009.62

12. Shen Y, Chiang P, Luo H, et al. Determine of the optimal number of cycles of docetaxel in the treatment of metastatic castration-resistant prostate cancer. Kaohsiung J Med Sci. 2016;32(9):458-463. doi:10.1016/j.kjms.2016.07.012

13. Kongsted P, Svane I, Lindberg H, Sengeløv L. Clinical impact of the number of treatment cycles in first-line docetaxel for patients with metastatic castration-resistant prostate cancer. Clin Genitourin Cancer. 2017;15(2):e281-e287. doi:10.1016/j.clgc.2016.08.019

14. Narita S, Koie T, Yamada S, et al. A prospective multicenter study of intermittent chemotherapy with docetaxel and prednisolone for castration-resistant prostate cancer. Jpn J Clin Oncol. 2016;46 (6):547-553. doi:10.1093/jjco/hyw021

15. Kume $H$, Kawai $T$, Nagata $M$, et al. Intermittent docetaxel chemotherapy is feasible for castration-resistant prostate cancer. Mol Clin Oncol. 2015;3(2):303-307. doi:10.3892/mco.2014.469

16. Mountzios I, Bournakis E, Efstathiou E, et al. Intermittent docetaxel chemotherapy in patients with castrate-resistant prostate cancer. Urology. 2011;77(3):682-687. doi:10.1016/j.urology.2010.08.044

17. Hussain M, Tangen C, Berry D, et al. Intermittent versus continuous androgen deprivation in prostate cancer. $N$ Engl J Med. 2013;368 (14):1314-1325. doi:10.1056/NEJMoa1212299

18. Cash H, Steiner U, Heidenreich A, et al. Intermittent vs continuous docetaxel therapy in patients with metastatic castration-resistant prostate cancer - a phase III study (PRINCE). BJU Int. 2018;122 (5):774-782. doi:10.1111/bju.14239

19. De Souza R, Zahedi P, Moriyama E, Allen C, Wilson B, PiquetteMiller M. Continuous docetaxel chemotherapy improves therapeutic efficacy in murine models of ovarian cancer. Mol Cancer Ther. 2010;9(6):1820-1830. doi:10.1158/1535-7163.Mct-10-0249

20. Takahashi M, Kusuhara Y, Mori H, et al. Long-Term Administration of Docetaxel Over 70 Cycles for Castration-Resistant Prostate Cancer. Clin Genitourin Cancer. 2015;13(4):e337-e340. doi:10.1016/j.clgc.2015.01.012 
21. Oudard S, Kramer G, Caffo O, et al. Docetaxel rechallenge after an initial good response in patients with metastatic castration-resistant prostate cancer. BJU Int. 2015;115(5):744-752. doi:10.1111/ bju. 12845

22. Caffo O, Pappagallo G, Brugnara S, et al. Multiple rechallenges for castration-resistant prostate cancer patients responding to first-line docetaxel: assessment of clinical outcomes and predictive factors. Urology. 2012;79(3):644-649. doi:10.1016/j.urology.2011.11.043
23. Thomas $\mathrm{C}$, Brandt $\mathrm{M}$, Baldauf $\mathrm{S}$, et al. Docetaxel-rechallenge in castration-resistant prostate cancer: defining clinical factors for successful treatment response and improvement in overall survival. Int Urol Nephrol. 2018;50(10):1821-1827. doi:10.1007/s11255-0181963-1

\section{Publish your work in this journal}

OncoTargets and Therapy is an international, peer-reviewed, open access journal focusing on the pathological basis of all cancers, potential targets for therapy and treatment protocols employed to improve the management of cancer patients. The journal also focuses on the impact of management programs and new therapeutic

Submit your manuscript here: https://www.dovepress.com/oncotargets-and-therapy-journal agents and protocols on patient perspectives such as quality of life, adherence and satisfaction. The manuscript management system is completely online and includes a very quick and fair peer-review system, which is all easy to use. Visit http://www.dovepress.com/ testimonials.php to read real quotes from published authors. 